\title{
ARTICLE
}

\section{Charcot spinal arthropathy: an increasing long-term sequel after spinal cord injury with no straightforward management}

\author{
Lukas Grassner ${ }^{1,2}$, Martina Geuther ${ }^{1}$, Orpheus Mach ${ }^{1}$, Volker Bühren ${ }^{1}$, Jan Vastmans ${ }^{1}$ and Doris Maier ${ }^{1}$
}

Charcot spinal arthropathy (CSA) is most likely increasing in patients suffering from consequences of spinal cord injury. We want to highlight initial symptoms, certain risk factors and perioperative complications of this condition. A single center retrospective case series in a specialized Center for Spinal Cord Injuries, BG Trauma Center Murnau, Germany highlighting the potential obstacles in the management of Charcot spine. We describe four female paraplegic patients (mean age: 50.75 years; range: 42-67), who developed Charcot spinal arthropathies. The mean age at the time of the accident was 21.5 years (3-35), the time lag after the accident before CSA was developed and finally diagnosed was on average 29.5 years (17-39) and the mean follow-up period was 39.5 months (6-73). Patient histories, initial symptoms, risk factors as well as the management and postoperative complications are provided. Charcot spine is an important potential sequel of spinal cord injury, which can lead to significant disability and spinal emergencies in affected individuals. More studies are needed to provide better recommendations for spine surgeons. Conservative treatment is an option. Posterior fixation alone does not seem to be sufficient.

Spinal Cord Series and Cases (2015) 1, 15022; doi:10.1038/scsandc.2015.22; published online 8 October 2015

\section{INTRODUCTION}

Jean-Martin Charcot first described neuroarthropathy in 1868 in a syphilitic patient. ${ }^{1}$ Since then this condition has commonly been described as 'Charcot spine'. In 1884, the first patient with spinal arthropathy has been reported. ${ }^{2}$ Theoretically every insult to the central or peripheral nervous system leading to an impairment of proprioceptive mechanisms can lead ultimately to the destruction of the vertebral column. Thus, a plethora of diseases such as diabetic neuropathy, tertiary syphilis, congenital absence of pain syndrome, syringomyelia as well as traumatic and non-traumatic spinal cord injury $(\mathrm{SCl})$ have been described to cause Charcot spinal arthropathy (CSA). ${ }^{3-6}$

After being described first in 1978 as a sequel of traumatic $\mathrm{SCl}^{7}$ the majority of cases with CSA was attributed to be a long-term complication of $\mathrm{SCl}^{4,8}$ As life expectancy of this patient cohort increases and with more surgical spine procedures being performed, Charcot spine is likely to be seen more frequently by spine specialists in the future. A better understanding of the pathophysiology, altered biomechanics and bone metabolism is needed to provide the best individual care for these patients. Surgical treatment has been proposed to deliver good long-term results, ${ }^{5}$ whereas the urge of surgery as a first-line treatment has been questioned most recently. ${ }^{9}$ Here we describe four patients, where the initial treatment did not provide satisfactory results or caused a high complication rate respectively.

\section{METHODS}

This analysis was performed at the Center for Spinal Cord Injuries (BG Trauma Center Murnau, Germany), a specialized surgical department in a level-I trauma center. The following study presents a retrospective chart review. To be included patient had to fulfill certain diagnostic and radiologic criteria for Charcot spine as previously described. ${ }^{4}$ Due to the retrospective character of the study, the complete absence regarding treatment interference and the clinical data sets being collected as part of institutional, national and international quality programs, a vote from the ethic committee was not indicated.

The main objective of this study was to highlight several surgical pitfalls in treating patients who developed CSA after SCl. Therefore, the complete medical records of all four selected patients were retrospectively reviewed to specify clinical and radiological findings.

\section{RESULTS}

In the following, we present four cases of CSA in patients living with the consequences of traumatic $\mathrm{SCl}$. All of the mentioned patients were female with a mean age of 50.75 years (range: 42-67) at the time when CSA was diagnosed. The mean age at the time of the accident was 21.5 years (3-35), the time lag after the accident before CSA was developed and finally diagnosed was on average 29.5 years (17-39) and the mean follow-up period was 39.5 months (6-73) (Table 1). The main goal is to highlight initial symptoms, risk factors, management and postoperative complications if applicable (Table 2).

\section{Case 1}

The first patient was a 67-year-old paraplegic woman. She was admitted to our institution with the suspected diagnosis of a massive spondylodiscitis at the level L2/3 from an outside hospital (Figures $1 \mathrm{~b}$ and $\mathrm{c}$ ). Her medical records showed a history of traumatic $\mathrm{SCl} 33$ years before presentation (with conservative initial treatment), posttraumatic syringomyelia and spondylodiscitis L2/3 4 years before (Figure 1a). We performed dorsal instrumentation L1-L4 (Figure 1d) without bone grafting and provided antibiotic long-term treatment (there was no evidence for bacterial infection, but antibiosis was already started 
Table 1. Demographic characteristics at the time when CSA was diagnosed

\begin{tabular}{|c|c|c|c|c|}
\hline & Patient 1 & Patient 2 & Patient 3 & Patient 4 \\
\hline Gender & Female & Female & Female & Female \\
\hline Age (years) & 67 & 42 & 50 & 44 \\
\hline AIS grade/level & A sub T3 & A sub $\mathrm{T} 4$ & A sub $T 12$ & B sub T6 \\
\hline Age at accident (years) & 35 & 3 & 20 & 28 \\
\hline Surgical treatment of $\mathrm{SCl}$ & No & No & $\begin{array}{l}\text { Dorsal instrumentation } \\
\text { +laminectomy }\end{array}$ & $\begin{array}{l}\text { Dorsal instrumentation+ } \\
\text { laminectomy }\end{array}$ \\
\hline Charcot lesions $(n)$ & 3 & 2 & 1 & 1 \\
\hline Level of CSA & $\mathrm{T} 12 / \mathrm{L} 1 ; \mathrm{L} 2 / 3, \mathrm{~L} 4 / 5$ & T8/9; L5/S1 & $\mathrm{L} 4 / 5$ & $\mathrm{~L} 3 / 4$ \\
\hline $\begin{array}{l}\text { Time lag betw. SCI-CSA } \\
\text { diagnosis (years) }\end{array}$ & 33 & 39 & 29 & 17 \\
\hline Follow-up (months) & 17 & 62 & 73 & 6 \\
\hline
\end{tabular}

Table 2. Initial symptoms, risk factors, management and complications

\begin{tabular}{|c|c|c|c|c|}
\hline & Patient 1 & Patient 2 & Patient 3 & Patient 4 \\
\hline Symptoms & $\begin{array}{l}\text { General discomfort, low } \\
\text { back pain }\end{array}$ & $\begin{array}{l}\text { Lumbar back pain, increased } \\
\text { spasticity, sitting imbalance }\end{array}$ & Sitting imbalance & $\begin{array}{l}\text { General discomfort, low back } \\
\text { pain, sitting imbalance }\end{array}$ \\
\hline $\begin{array}{l}\text { Additional } \\
\text { risk factors }\end{array}$ & $\begin{array}{l}\text { Posttraumatic } \\
\text { Syringomyelia }\end{array}$ & $\begin{array}{l}\text { Secondary } \\
\text { scoliosis }\end{array}$ & $\begin{array}{l}\text { Ankylosing spondylitis, } \\
\text { type II diabetes }\end{array}$ & $\begin{array}{l}\text { Idiopathic } \\
\text { scoliosis }\end{array}$ \\
\hline Treatment & $\begin{array}{l}\text { Dorsal stabilization } \\
\text { (L1-L4) }\end{array}$ & $\begin{array}{l}\text { Shortening of inserted } \\
\text { Harrington rod }\end{array}$ & Conservative & $\begin{array}{l}\text { Dorsal stabilization } \\
\text { (L2/3-L5) }\end{array}$ \\
\hline Complications & $\begin{array}{l}\text { Wound dehiscence, implant } \\
\text { loosening, adjacent segment } \\
\text { Charcot lesions }\end{array}$ & $\begin{array}{l}\text { Adjacent segment } \\
\text { Charcot } \\
\text { lesions }\end{array}$ & $\begin{array}{l}\text { Further disease } \\
\text { progression }\end{array}$ & $\begin{array}{l}\text { Implant loosening, } \\
\text { wound healing } \\
\text { disturbances }\end{array}$ \\
\hline
\end{tabular}

empirically). One month later she required revision surgery due to wound dehiscence. After 1 year she developed general discomfort, low back pain and sitting imbalance again. Radiologic workup revealed CSA lesion in adjacent segments and implant loosening (Figure 1e). The dorsal instrumentation was further removed and conservative treatment via a back brace was initiated with no progression upon clinical and radiological examination over time.

\section{Case 2}

This female patient was admitted to our service because of lumbar back pain, increased spasticity and sitting imbalance. Radiologic examination showed a massive fluid-filled substance defect in the lumbosacral region (Figure 2a). She was dealing with the consequences of paraplegia due to traumatic thoracic $\mathrm{SCl}$ since 39 years and spinal surgery with Harrington rods due to secondary neuropathic scoliosis 26 years ago (Figure $2 \mathrm{~b}$ ). Her medical condition refused major spine surgery. The inserted Harrington rod was shortened at the caudal end (Figure 2c) and conservative treatment was initiated. Over the years no disease progression was observed in the lumbar region, but adjacent CSA lesion was observed rostral to the instrumentation material (Figure 2d).

\section{Case 3}

During a radiologic control examination due to discrete sitting imbalance and mild low back pain for a couple of months, a CSA lesion was found at the level of $L 4 / 5$ (Figures $3 b$ and $c$ ) in a paraplegic 50-year-old woman. An examination 4 years earlier showed radiologic signs of ankylosing spondylitis (Figure 3a). Her medical history was also indicative for type II diabetes and morbid obesity. Due to the relatively low burden of disease, the patient underwent conservative management with a back brace (Figure 3d).

\section{Case 4}

This 44-year-old woman was sent to our department with the suspected diagnosis of spondylodiscitis at the level L3/L4 with coexisting abscesses in the psoas muscle bilaterally (Figure 4a). She presented with low back pain, an audible crepitus upon transfer and general discomfort for 10 days. Her past medical history was significant for motor complete, sensory incomplete paraplegia below the level of T6 since 17 years and preexisting idiopathic scoliosis, which required several spine surgeries even her traumatic SCl. Needle biopsies did not show any evidence regarding bacterial infection. A posterior percutaneous fixation was carried out from L2/L3 to L5 without any bone grafting (Figure 4b).

Ten days after surgery the patient realized a different cracking noise and the feeling of sitting imbalance immediately after mobilization into her wheelchair. The following X-ray investigation showed an implant loosening (Figure 4c). Because the patient refused revision surgery with a circumferential approach, the dorsal spondylodesis was completely removed. Postoperatively she developed wound-healing disturbances. After approximately 6 months no further disease progression was observed after conservative treatment (Figure $4 d$ ).

\section{DISCUSSION}

Neurogenic arthropathy involves extensive disc degeneration as well as massive vertebral degeneration with coexisting osteosclerosis and additional bone formation at the same time. This eventually results in dislocation and instability of the vertebral column ${ }^{4}$ as seen in all of our presented patients. The most accepted pathophysiological hypothesis highlights the initial loss of proprioception and pain/temperature sensation. This leads to altered joint defense mechanisms and abnormal stress in these joints. Moreover, the loss of sympathetic innervation probably has an essential role in the 

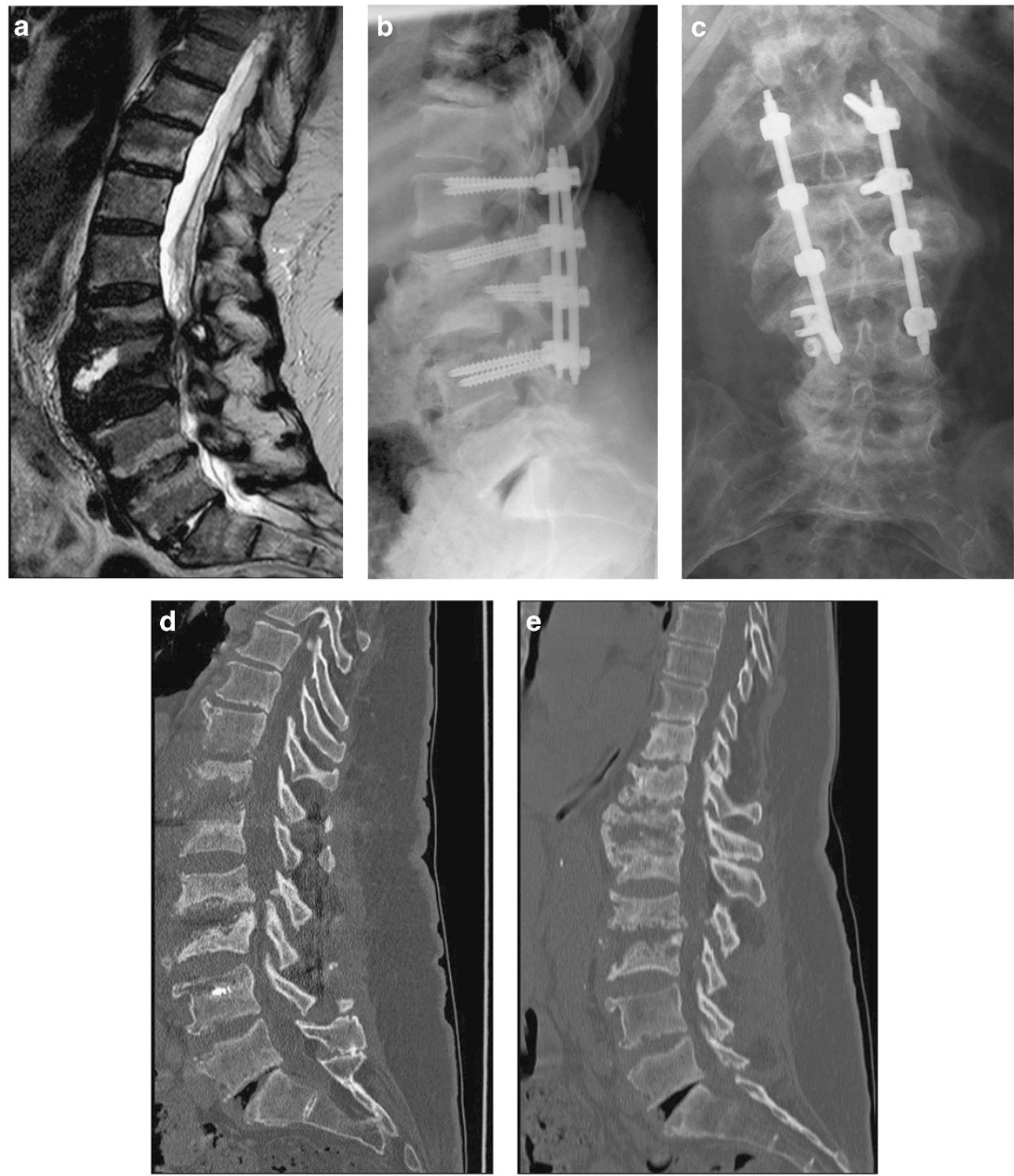

Figure 1. Patient 1. (a) Sagittal T2-weighted MR image of the lumbar spine 4 years later to a; (b) lateral X-ray showing dorsal spondylodesis; (c) Anterior-posterior X-ray showing implant loosening 1 year after (d); (d) Sagittal CT indicating Charcot spine lesions in adjacent segments; (e) Sagittal CT 7 months after (d).
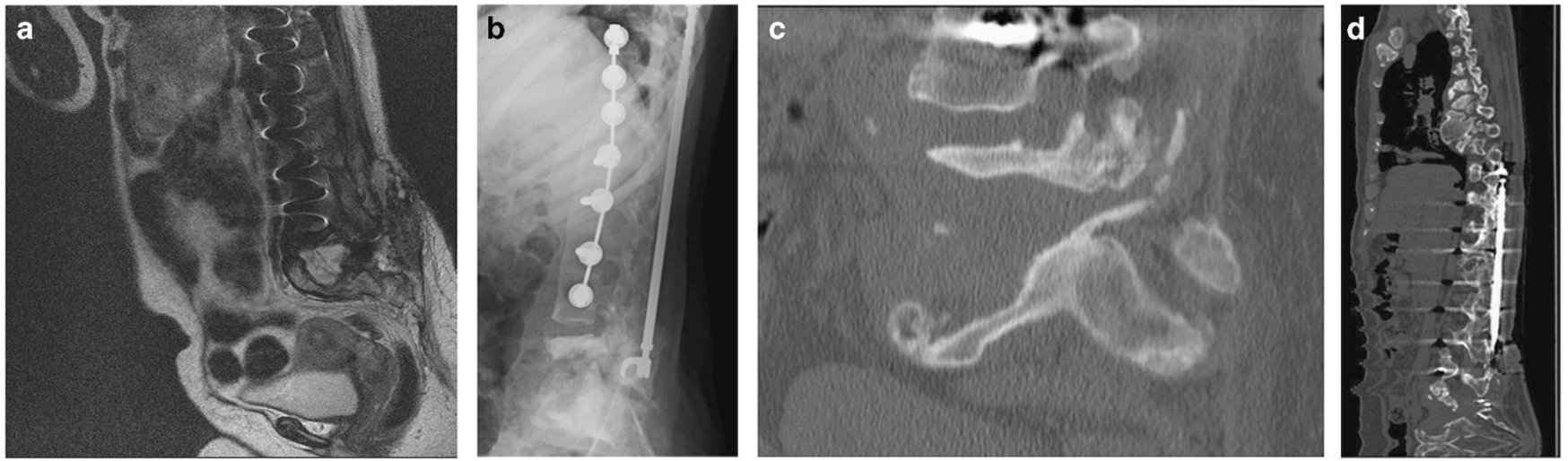

Figure 2. Patient 2. (a) Sagittal T2-weighted MR image showing a lumbosacral substance defect; (b) Lateral X-ray 3 years before (a); (c) According sagittal CT image to a; (d) Sagittal CT 4 years after (a) showing shortening of Harrington rod and adjacent CSA above the instrumentation. 

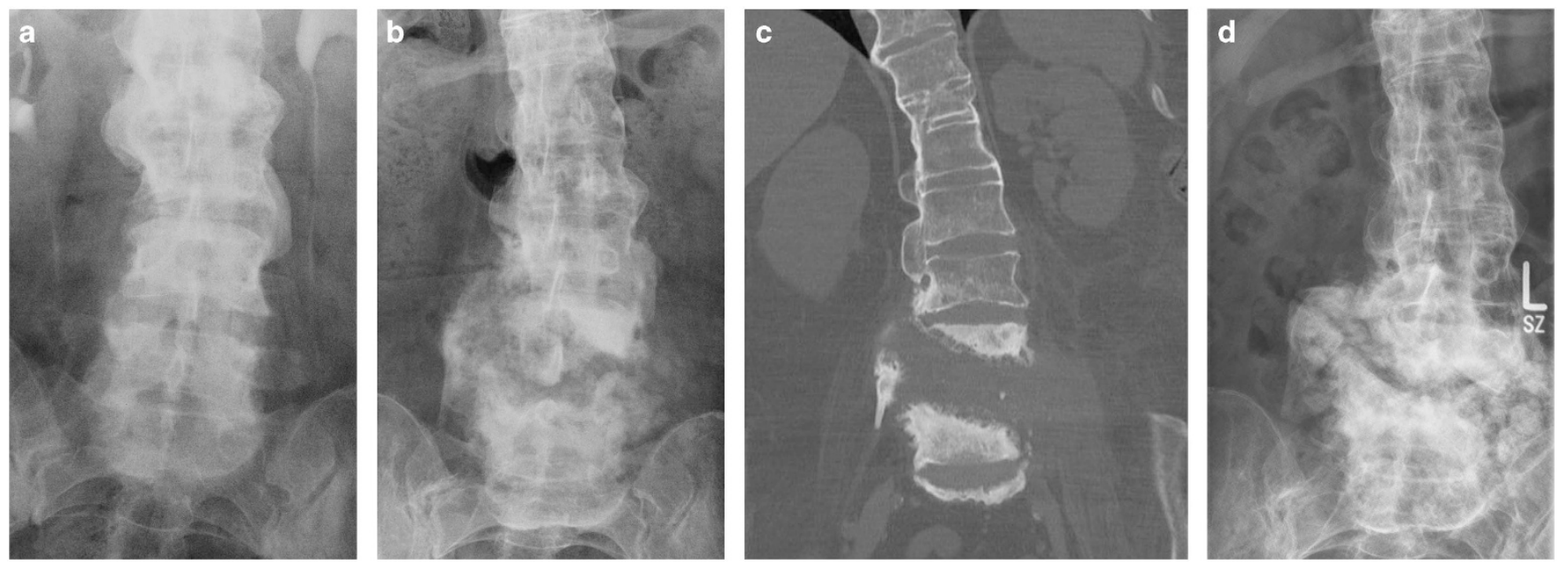

Figure 3. Patient 3. (a) X-ray taken during an urodynamic control examination showing signs of ankylosing spondylitis 4 years before (b). (b) X-ray with a CSA lesion at the level of L4/5. (c) According coronar CT to b. (d) X-ray after a 6-year follow-up period showing radiologic progression with a clear pseudotumoral appearance.
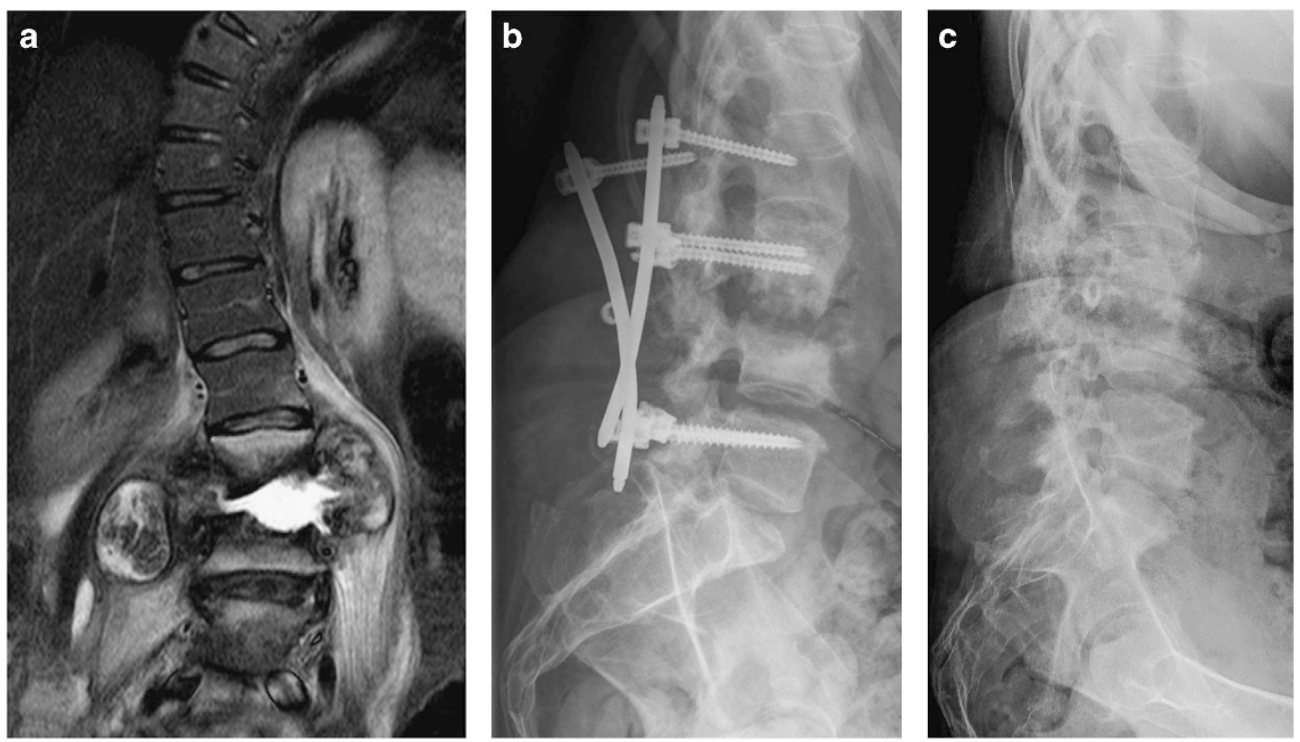

Figure 4. Patient 4. (a) Coronar T2-weighted MR image showing a fluid-filled disc space at the level of L3/4 with significant bone destruction and paravertebral abscess formation; (b) lateral X-ray highlighting implant loosening; (c) lateral X-ray showing similar erosion to prior examinations.

multi-faceted occurrence of Charcot spine (for further reading please see Barrey et al. ${ }^{4}$ ).

Previously suggested diagnostic criteria are: ${ }^{4,5}$

- Presence of an underlying disease, which impairs adequate proprioception and pain sensation.

- Bone destruction and resorption as well as new bone formation on radiological examinations.

- Evidence of non-specific chronic inflammation on histologic examination.

These processes lead to several radiologic features: ${ }^{4,5,10-12}$

- Profound disc generation (seen in all presented cases).

- Vertebral destruction/erosion accompanied with osteolysis and/ or osteosclerosis (seen in all presented individuals).
- Hypertrophic hyperostosis within surrounding soft tissue, with a 'pseudotumoral' appearance.

- Early destructive changes are seen at the facet joints.

In SCl patients-especially in active paraplegic patients (like patients 1,2 and 4)-the thoracolumbar and lumbosacral spine is especially susceptible to develop Charcot lesions because excessive loads are operating repetitively on this area. ${ }^{5}$ In paraplegic patients lumbar lordosis is flattened and kyphosis might develop, which may intensify further degenerative changes. ${ }^{13,14}$ This explains the predominance of the mentioned spine areas (as also seen in cases 1-4), where the L3/4 segment seems to be affected the most. ${ }^{4}$

Other risk factors may include spinal fusion and laminectomy for the treatment of $\mathrm{SCl}$ as well as very active paraplegic patients. ${ }^{5,8,15,16}$ We want to highlight the relative frequency 
of scoliosis, either idiopathic (patient 4) or secondary to $\mathrm{SCl}$ (patient 2) in this series. Since diabetic neuropathy and syringomyelia are risk factors per $s e_{1}^{3,6}$ it seems logical that their concomitant presence (patients 1 and 3) might boost the development of CSA. Ankylosing spinal hyperostosis (patient 3) might be another risk factor. ${ }^{3}$

Patients may present with a variety of different symptoms. Sitting imbalance, an audible cracking noise upon transfer, pain in an otherwise insensitive area and a change in the neurological status seem to be the most frequent ones. ${ }^{3,4,8,13}$ Noteworthy changes in the spasticity, usually toward a flaccid paralysis might occur at the time of CSA diagnosis. ${ }^{3}$ Interestingly patient 2 presented with increased spasticity, but this might have also been present due to a urinary tract infection at that time. Increased episodes of autonomic dysreflexia might also be indicative for CSA. ${ }^{4,17}$

The main differential diagnoses are tumorous or infectious processes. $^{4,18,19}$ Unfortunately, there are no pathognomonic features that can help to differentiate among these. Two of the aforementioned patients were sent to our institution with the suspected diagnosis of acute spondylodiscitis. These patients also showed general discomfort and elevated leukocytosis. A paravertebral mass or abscess can be evident in Charcot spine (as seen in patient 4) as well as in spondylodiscitis. It is challenging to discriminate between spondylodiscitis and a superinfected Charcot spine if the detailed patient history is not present. ${ }^{20,21}$ Furthermore, patients suffering from recurrent infections (for example, urinary tract infections) are more likely to develop spinal infections. ${ }^{4}$ A needle biopsy-ideally before the initiation of empiric antibiotic treatment-should be centered in the disc space to help in the distinction. Tissue pathology of Charcot spine involves fibrosis without any indications for acute inflammation, normal granulation tissue and osteosclerosis without any signs of malignancy. ${ }^{4}$ Sometimes a tumoral process, like a paravertebral mass, is present in spinal arthropathy. ${ }^{22}$ It is crucial to obtain a biopsy or remove the mass during surgery.

In the published literature, CSA develops around 17.3 years after the initial trauma (in this study after 29.5 years). In about two-thirds of the patients Charcot spine affects only one segment, whereas two joints are impacted in more than $25 \%$ and three joints in the remaining. ${ }^{4}$ These numbers are also reflected in this case series. The fact, that only female patients are described here, although a clear male predominance has been reported, might just be a coincidence. ${ }^{3,4}$

Surgical treatment is able to deliver excellent long-term results and the outcome might be slightly better in the spine than for Charcot arthropathies in the limbs. ${ }^{5}$ However, conservative treatment should be considered ${ }^{9}$ and is sometimes necessary due to the medical condition of these patients (our own experience). Postoperative complications include implant loosening (especially if only dorsal instrumentation has been performed as seen in patients 1 and 4), wound healing delays and the development of additional Charcot lesion either within or adjacent to the operated area (patients 1,2 and 4$).{ }^{8}$ If surgery is performed, then a stable reconstruction of all three spine columns, especially the anterior one is necessary. In our opinion, a circumferential arthrodesis with a single staged posterolateral approach ${ }^{23}$ seems to be an attractive option in complete paraplegic patients.

In general the vague clinical presentation with the potential severe clinical impact of CSA, emphasizes the value of regular, long-term clinical and radiological follow-up of spinal cord-injured patients in specialized centers.

\section{DATA ARCHIVING}

There were no data to deposit.

\section{ACKNOWLEDGEMENTS}

We thank the institutional radiology department for the good collaboration

\section{COMPETING INTERESTS}

The authors declare no conflict of interest.

\section{REFERENCES}

1 Charcot JM. Sur quelques arthropathies qui paraissant dependre dune lesion due cerveau ou de la modelle epiniere. Arch Physiol Norm Pathol 1868; 1: 161.

2 Kroning G. Spondylolisthese bei einem Tabiker. Zeit Klin Med 1884; suppl 7, 165.

3 Morita M, Miyauchi A, Okuda S, Oda T, Yamamoto T, Iwasaki M. Charcot spinal disease after spinal cord injury. J Neurosurg Spine 2008; 9, 419-426.

4 Barrey C, Massourides H, Cotton F, Perrin G, Rode G. Charcot spine: two new case reports and a systematic review of 109 clinical cases from the literature. Ann Phys Rehabil Med 2010; 53, 200-220.

5 Suda Y, Shioda M, Kohno H, Machida M, Yamagishi M. Surgical treatment of Charcot spine. J Spinal Disord Tech 2007; 20, 85-88.

6 Silber JS, Vaccaro AR, Green B. Summary statement: chronic long-term sequelae after spinal cord injury: post-traumatic spinal deformity and post-traumatic myelopathy associated with syringomyelia. Spine (Phila Pa 1976) 2001; 26, S128.

7 Slabaugh PB, Smith TK. Neuropathic spine after spinal cord injury. A case report. J Bone Joint Surg Am 1978; 60, 1005-1006.

8 Aebli N, Potzel T, Krebs J. Characteristics and surgical management of neuropathic (Charcot) spinal arthropathy after spinal cord injury. Spine J 2014; 14, 884-891.

9 Moreau S, Lonjon G, Jameson R, Judet T, Garreau de Loubresse C. Do all Charcot Spine require surgery? Orthop Traumatol Surg Res 2014; 100, 779-784.

10 Harrison MJ, Sacher M, Rosenblum BR, Rothman AS. Spinal Charcot arthropathy. Neurosurgery 1991; 28, 273-277.

11 Vaccaro AR, Silber JS. Post-traumatic spinal deformity. Spine (Phila Pa 1976) 2001; 26, S111-S118.

12 Brown CW, Jones B, Donaldson DH, Akmakjian J, Brugman JL. Neuropathic (Charcot) arthropathy of the spine after traumatic spinal paraplegia. Spine (Phila $\mathrm{Pa}$ 1976) 1992; 17, S103-S108.

13 De lure F, Chehrassan M, Cappuccio M, Amendola L. Sitting imbalance cause and consequence of post-traumatic Charcot spine in paraplegic patients. Eur Spine J 2014; 23(Suppl 6), 604-609.

14 Seelen HA, Potten YJ, Huson A, Spaans F, Reulen JP. Impaired balance control in paraplegic subjects. J Electromyogr Kinesiol 1997; 7, 149-160.

15 Sobel JW, Bohlman HH, Freehafer AA. Charcot's arthropathy of the spine following spinal cord injury. A report of five cases. J Bone Joint Surg Am 1985; 67, 771-776.

16 Standaert C, Cardenas DD, Anderson P. Charcot spine as a late complication of traumatic spinal cord injury. Arch Phys Med Rehabil 1997; 78, 221-225.

17 Selmi F, Frankel HL, Kumaraguru AP, Apostopoulos V. Charcot joint of the spine, a cause of autonomic dysreflexia in spinal cord injured patients. Spinal Cord 2002; 40, 481-483.

18 Jones EA, Manaster BJ, May DA, Disler DG. Neuropathic osteoarthropathy: diagnostic dilemmas and differential diagnosis. Radiographics 2000; 20 Spec No, S279-S293.

19 Vialle R, Mary P, Tassin JL, Parker F, Guillaumat M. Charcot's disease of the spine: diagnosis and treatment. Spine (Phila Pa 1976) 2005; 30, E315-E322.

20 Suda Y, Saito M, Shioda M, Kato H, Shibasaki K. Infected Charcot spine. Spinal Cord 2005; 43, 256-259.

21 Mikawa Y, Watanabe R, Yamano Y, Morii S. Infected Charcot spine following spinal cord injury. Spine (Phila Pa 1976) 1989; 14, 892-895.

22 Son SB, Lee SH, Kim ES, Eoh W. Charcot arthropathy of the lumbosacral spine mimicking a vertebral tumor after spinal cord injury. J Korean Neurosurg Soc 2013; 54, 537-539.

23 Kim TW, Seo EM, Hwang JT, Kwak BC. Charcot spine treated using a single staged posterolateral costotransversectomy approach in a patient with traumatic spinal cord injury. J Korean Neurosurg Soc 2013; 54, 532-536. 